\title{
Adiposity markers and lung function in smokers: a cross-sectional study in a Mediterranean population
}

\author{
Mar Sorlí-Aguilar ${ }^{1,2}$, Francisco Martín-Luján 1,3,4*, Gemma Flores-Mateo², Cristina Jardí-Piñana ${ }^{3}$, \\ Estefania Aparicio-Llopis ${ }^{3}$, Josep Basora-Gallisà ${ }^{2,3,5}$, Rosa Solà-Alberich ${ }^{3,6}$ and for the ESPITAP Study Group \\ investigators
}

\begin{abstract}
Background: The aim of this study was to assess the association of key adiposity markers with lung function in smokers without respiratory disease in a Mediterranean population.

Methods: We performed a cross-sectional study with baseline data from a representative sample of the ESPITAP study in Spain. Participants were 738 smokers (52.3\% men) without respiratory disease, aged 35 to 70 , selected from 12 primary health care centres. We assessed weight, height, body mass index (BMI), waist circumference (WC) and waist-to-height ratio (WHtR). The pulmonary functional parameters were forced vital capacity (FVC), forced expiratory volume in $1 \mathrm{~s}$ (FEV1) and FEV1/FVC ratio.

Results: In this cohort of smokers, 22.2\% of individuals had central obesity. FVC\% was inversely associated with all anthropometric measures (BMI, WC and WHtR) in the overall population and in men; in women, only BMI was associated with FVC\%. FEV1\% was inversely associated to BMI and WC in the overall population, and to all anthropometric measures in men. Furthermore, both BMI and obesity were positively associated with FEV1/FVC ratio overall and when stratified by sex; this suggests a restrictive pattern explained by the altered ventilator mechanics experienced by people with obesity.

Conclusion: In a Mediterranean population of smokers without respiratory symptoms, abdominal obesity, evaluated not only by BMI and WC but also WHtR, is inversely associated with lung function. Fat distribution appears more strongly related to pulmonary function parameters in men than in women. In smokers with high values for WC, WHtR and BMI, assessment of lung function is recommended.
\end{abstract}

Trial registration: Current Controlled Trials NCT01194596. Registered 2 September 2010.

Keywords: Lung function test, Overweight, Obesity, Waist circumference, Tobacco smoke

\section{Background}

Smoking is an established cause of diseases and is responsible for most of the avoidable deaths in smokers due to cardiovascular diseases, respiratory diseases and cancer [1]. Tobacco smokers have reduced lung function, characterized by decreased forced expiratory volume after

\footnotetext{
* Correspondence: fmartin.tgn.ics@gencat.cat

'Study Group on Respiratory Tract Diseases (GEPAR), Institut Universitari d'Investigació en Atenció Primària Jordi Gol (IDIAP Jordi Gol), Barcelona, Spain

${ }^{3}$ School of Medicine and Health Sciences, Universitat Rovira i Virgili,

Tarragona, Spain

Full list of author information is available at the end of the article
}

one second (FEV1) and forced vital capacity (FVC) in diagnostic tests, and smoking has been associated with environmental risks, genetic disorders, respiratory infections, poor dietary habits and obesity [2]. However, other factors such as body weight can exert an influence on lung function [3]. Specifically, excess weight has a negative impact on the respiratory system due to its effect on gas exchange, respiratory mechanics, muscular endurance and breath control $[4,5]$. No consensus exists about the physiopathological mechanisms by which excess weight leads to respiratory complications, although it seems that these include mechanical impact on the diaphragm 
(impeding descent into the abdominal cavity) or on the chest wall (changes in compliance, the work of breathing and elastic recoil) [6].

Respiratory complications have been consistently reported in patients with obesity, a chronic disease characterized by the excessive accumulation of body fat and associated with a reduction in lung volume. Body fat can be measured using the body mass index (BMI) and classified into categories according to World Health Organization criteria [7]. The role of BMI relative to the risk of impaired lung function has been well studied. The most consistent effect is an exponential decrease in FEV1\% and in functional residual capacity with increasing BMI [8-11]. On the other hand, a low BMI is associated with increased risk of mortality and is considered a negative prognostic factor for survival based on the degree of lung dysfunction $[6,12]$.

Nevertheless, studies using weight and BMI as the single relevant measurements of adiposity while ignoring other aspects of body composition, such as visceral fat or fat distribution, may miss the true dose-response curve between the distribution of adiposity and increased risk of disease or all-cause mortality. A recent systematic review and meta-analysis of the impact of adiposity distribution has clearly shown a significant inverse relationship between waist circumference (WC) and pulmonary function, with a greater effect size in men [13]. Furthermore, waistto-height ratio (WHtR) and other indexes of fat distribution have been suggested to better identify high-risk subjects of different pathologies [14, 15]. WHtR has the benefit of adjusting WC according to height, a measurement that remains quite unchanged in adults; this reinforces the importance of changes in WC measurement. These newer indexes have even replaced BMI in several definitions for clinical diagnosis of metabolic syndrome that consider fat distribution a more accurate predictor of diabetes of cardiovascular disease [16]; however, they are not widely used in studies of respiratory function or diseases.

The aim of the present study was to assess the association between body weight, new indexes of fat distribution and lung function in a Mediterranean population of smokers with no diagnosis of respiratory disease.

\section{Methods}

\section{Study design}

A cross-sectional study was performed with baseline data from a representative sample of the ESPITAP study (Spanish acronym for "Effectiveness of Smoking Cessation Advice Combined with Spirometric Results in Adult Smokers"). This multicentre, randomized, clinical trial aimed to evaluate the effectiveness in the primary care setting of a structured motivational intervention and feedback on spirometry data to achieve smoking cessation, compared with usual clinical practice and assessed with respect to quit rates at 12 months after the intervention. The detailed protocol of the ESPITAP study has been previously published [17].

\section{Study subjects}

Of the 195,343 patients aged 18 years and older from 12 primary care practices in the province of Tarragona (Spain) managed by the Catalan Health Institute who were randomized to the ESPITAP study groups, 738 were selected. Candidates for participation were smokers who visited a centre for any reason during regular office hours, met all inclusion criteria and none of the exclusion criteria (detailed below), and signed informed consent.

\section{Inclusion criteria}

Aged 35 to 70 years, current smoker (defined as having smoked daily during the past month, regardless of the quantity), cumulative consumption of more than 10 pack-years (defined as the daily average of cigarettes smoked, multiplied by the number of years of smoking, divided by 20 cigarettes in a pack). Exclusion criteria: any evidence of previous diagnosis of a respiratory disease, functional pulmonary testing conducted within the previous 12 months, presence of any chronic or terminal condition that would affect the baseline parameters or complicate the testing and analysis to be conducted during the study period, impossibility of completing follow-up for any reason, or patient refusal to participate in the study.

\section{Measurements}

The baseline examination included a structured questionnaire designed to collect the necessary data: sociodemographic, history of diseases, medications and symptoms, alcohol consumption (standard drink unit/week), physical activity (hours/week), current daily smoking habit (cigarettes per day) and accumulated consumption (lifetime tobacco exposure in pack-years).

\section{Lung function}

Spirometry and bronchodilator tests were administered using a Datospir-600 ultrasound pneumotachograph (SIBELMED, S.A.), following a standardized procedure according to current recommendations [18]. The following criteria were used to determine normal pneumotachography values: $\mathrm{FEV} 1 \geq 80 \%$ of the predicted value, $\mathrm{FVC} \geq 80 \%$ of the predicted value, and FEV1/FVC $\geq 0.7$ [19].

\section{Anthropometry and body composition}

During a physical examination, height $(\mathrm{m})$ and weight $(\mathrm{kg})$ were measured with the participant in light clothing and no shoes, using calibrated scales and a wall-mounted stadiometer, respectively; BMI was calculated as the weight (kilograms) divided by the square of the height (meters). 
World Health Organization criteria were used to classify the population according to weight status (normal weight, BMI $<25.0 \mathrm{~kg} / \mathrm{m}^{2}$; overweight, BMI $25.0-29.9 \mathrm{~kg} / \mathrm{m}^{2}$ and obesity, BMI $\geq 30.0 \mathrm{~kg} / \mathrm{m}^{2}$ ) [7]; WC was measured midway between the lowest rib and the iliac crest using an anthropometric tape; the WHtR was calculated as WC divided by height, both in centimetres.

\section{Sample size}

Accepting an alpha risk of 0.05 in a two-sided test with 243 subjects in the first group (normal weight) and 175 in the second group (obesity), the statistical power was greater than $99 \%$ to recognize as statistically significant a difference of means (97.9 of $\mathrm{FVC} \%$ in normal-weight group and 87.8 of $\mathrm{FVC} \%$ in obesity group). Moreover, accepting an alpha risk of 0.05 in a two-sided test with 243 subjects in the first group (normal weight) and 303 in the second group (overweight), the statistical power was $98 \%$ to recognize as statistically significant a difference of means (97.9 of $\mathrm{FVC} \%$ in normal weight group and 92.8 of FVC\% in overweight group).

\section{Statistical analysis}

Quantitative variables were expressed as mean and standard deviation (SD) or median and range depending on the normal distribution of variable. We evaluated the association of categories of body weight and fat distribution measures with lung function according to the spirometry results. First, a Pearson correlation was performed to investigate association between weight, height, BMI, WC and WHtR and FVC\%, FEV1\% and FEV1/FVC ratio. Later, a multivariate linear regression analysis was performed for all participants and for men and women separately, applying the Full Maximum likelihood method of estimation. BMI $<25 \mathrm{~kg} / \mathrm{m}^{2}$ was used as reference value.

We applied Holm-Bonferroni corrections for multiple testing to $p$-values resulting from the Pearson correlation [20].

All statistical tests were 2-sided at the $5 \%$ significance level. Analyses were carried out using the Stata/MP 14.1 version (Stata Corp).

\section{Results}

A total of 738 participants (52.3\% men) were included. The baseline characteristics of the study participants are shown in Table 1. There were no significant differences between men and women in age, sociodemographic data, medical history or BMI, though men tended to be taller and heavier than women. Approximately $41 \%$ of the study population was overweight and $24 \%$ was obese, with higher values in men. The mean (SD) age of smoking onset was lower in men $(17.10 \pm 4.73$ years vs. 18.71 \pm 6.44 for women) and women smoked less $(17.63 \pm 9.30$ cigarettes a day vs. $20.72 \pm 11.94$ for men). FVC\%, FEV1 \% and FEV1/FVC ratio were lower in men.

The correlation between the anthropometric measures and lung function are shown in Table 2 . FVC \% was inversely correlated with body weight $(r=-0.203)$, BMI $(r=-0.236)$, WC $(r=-0.267)$ and WHtR $(r=-0.261)$, but only in men. Furthermore, FEV1\% was associated with WC $(r=-0.226)$ and WHtR $(r=-0.218)$ only in men. No association was found between FEV1/FVC ratio and the adiposity measures (BMI, WC and WHtR).

A multivariate linear regression analysis of lung function parameters and anthropometric measures, overall and separately for men and women, are shown in Table 3. FVC\% was inversely and significantly associated with all anthropometric measures in the overall population (WHtR, $p=$ 0.002 ; WC, $p<0.001$; continuous BMI, $p<0.001$; BMI $\geq 30$, $p<0.001$ ) and men (WHtR, $p=0.001$; WC, $p<0.001$; continuous BMI, $p<0.001$; $\mathrm{BMI} \geq 30, p<0.001)$. By contrast, only continuous BMI was inversely associated with $\mathrm{FVC} \%$ in women $(p=0.016)$. Likewise, FEV1\% was inversely associated only with WC and continuous BMI in the overall population ( $p=0.005$ and $p=0.024$, respectively), but with all anthropometric measures in men (WHtR, $p=0.007$; WC, $p=0.002$; continuous BMI, $p=0.029$; BMI $\geq 30$, $p=0.054)$. In women, none of the anthropometric indices was significantly associated with FEV1\%. Finally, FEV1/FVC ratio was positively associated with BMI categorization and continuous BMI in the overall population and in men and women when analysed separately.

\section{Discussion}

This study, conducted in a Mediterranean population of smokers without pulmonary disease, showed that overweight, obesity and pattern of body fat distribution are inversely related to lung function. A positive association was found between FEV1/FVC ratio and BMI, overweight and obesity categories in both sexes. Moreover, a negative correlation was found between BMI, WC and WHtR and both FVC\% and FEV1\% in all smokers, but especially in men. These new adiposity markers provide evidence from a Mediterranean population of smokers and complement the findings of previous cross-sectional and prospective studies in other populations showing that an excess of adipose tissue and its distribution pattern are negatively related to pulmonary function, a basic indicator of respiratory health $[8,9,21,22]$.

The present study has both limitations and strengths to consider. Cross-sectional analysis was used to assess the ability of adiposity marker measures to predict a pulmonary function disorder, making inference of causality difficult. Further longitudinal analysis will provide stronger evidence of these associations. Smoking status, which has a detrimental effect on the lungs, is a potential confounding factor in the relationship between BMI, 
Table 1 Characteristics and lung function measures of the study sample, overall and separately for men and women

\begin{tabular}{|c|c|c|c|}
\hline Variables & Men $(n=386)$ & Women $(n=352)$ & All $(n=738)$ \\
\hline \multicolumn{4}{|l|}{ Sociodemographic } \\
\hline Age, years & $52.87 \pm 8.23$ & $48.90 \pm 7.39$ & $50.98 \pm 8.08$ \\
\hline \multicolumn{4}{|l|}{ Marital status, n (\%) } \\
\hline Married & $299(77.5)$ & $226(64.2)$ & $525(71.1)$ \\
\hline Widower & $3.0(0.8)$ & $19(5.4)$ & $22(3.0)$ \\
\hline Single & $46(12.0)$ & $39(11.1)$ & 85 (11.6) \\
\hline Separated/Divorced & $35(9.1)$ & $66(18.9)$ & $101(13.8)$ \\
\hline \multicolumn{4}{|l|}{ Social class ${ }^{a}, n(\%)$} \\
\hline High & $62(16.1)$ & $51(14.5)$ & $113(15.4)$ \\
\hline Medium & $176(46.0)$ & $148(42.0)$ & $324(43.9)$ \\
\hline Low & $145(37.6)$ & $151(42.9)$ & $296(40.1)$ \\
\hline \multicolumn{4}{|l|}{ Medical history, n (\%) } \\
\hline Diabetes mellitus & $49(12.7)$ & $18(5.1)$ & $67(9.1)$ \\
\hline Dyslipidaemia & $115(29.8)$ & $64(18.2)$ & $179(24.3)$ \\
\hline Hypertension & $112(29.0)$ & $68(19.3)$ & $180(24.4)$ \\
\hline Cardiovascular disease & $18(4.7)$ & $4(1.1)$ & $22(3.0)$ \\
\hline Central obesity & $72(18.6)$ & $92(26.1)$ & $164(22.2)$ \\
\hline \multicolumn{4}{|l|}{ Health habits } \\
\hline Alcohol consumption, standard drink/week & $7(0-9)$ & $0(0-2)$ & $1(0-9)$ \\
\hline Physical activity, hours/week & $2.42 \pm 0.26$ & $2.20 \pm 0.19$ & $2.31 \pm 0.16$ \\
\hline \multicolumn{4}{|l|}{ Smoking } \\
\hline Start smoking age, years & $17.10 \pm 4.73$ & $18.71 \pm 6.44$ & $17.87 \pm 5.65$ \\
\hline Current consumption, cigarettes/day & $20.72 \pm 11.94$ & $17.63 \pm 9.30$ & $19.25 \pm 10.87$ \\
\hline Cumulative consumption, pack-years & $36.77 \pm 23.55$ & $26.96 \pm 16.62$ & $32.09 \pm 21.10$ \\
\hline \multicolumn{4}{|l|}{ Anthropometric and body composition } \\
\hline Weight, kg & $80.38 \pm 13.46$ & $66.82 \pm 14.15$ & $73.92 \pm 15.36$ \\
\hline Height, cm & $170.30 \pm 6.93$ & $158.35 \pm 6.79$ & $164.61 \pm 9.09$ \\
\hline $\mathrm{BMI}, \mathrm{kg} / \mathrm{m}^{2}$ & $27.63 \pm 0.22$ & $26.65 \pm 0.28$ & $27.16 \pm 0.17$ \\
\hline \multicolumn{4}{|l|}{ BMI categorization ${ }^{\mathrm{b}}, \mathrm{n}(\%)$} \\
\hline$<25.0 \mathrm{~kg} / \mathrm{m}^{2}$ & $90(23.3)$ & $153(44.5)$ & $243(32.9)$ \\
\hline $25.0-29.9 \mathrm{~kg} / \mathrm{m}^{2}$ & $184(47.7)$ & $119(33.8)$ & $303(41.1)$ \\
\hline$\geq 30.0 \mathrm{~kg} / \mathrm{m}^{2}$ & $102(26.4)$ & $73(21.2)$ & $175(23.7)$ \\
\hline Waist circumference, cm & $98.75 \pm 10.44$ & $92.27 \pm 16.55$ & $96.0 \pm 13.73$ \\
\hline Waist-to-height ratio & $0.58 \pm 0.06$ & $0.59 \pm 0.10$ & $0.58 \pm 0.82$ \\
\hline \multicolumn{4}{|l|}{ Lung function parameters } \\
\hline FVC, $\%$ of predicted & $89.14 \pm 0.84$ & $98.10 \pm 0.77$ & $93.49 \pm 0.59$ \\
\hline FEV1, \% of predicted & $90.50 \pm 0.96$ & $99.73 \pm 0.82$ & $94.93 \pm 0.66$ \\
\hline FEV1/FVC ratio (\%) & $76.13 \pm 0.40$ & $78.59 \pm 0.35$ & $77.32 \pm 0.27$ \\
\hline
\end{tabular}

Data are presented as number of patients (\%) or mean \pm standard deviation or median \pm range depending on the type of variable

$B M I$ Body mass index, SBP Systolic blood pressure, DBP Diastolic blood pressure, ppm Parts per million, FVC Forced vital capacity, FEV1 Maximum expiratory

volume in the first second of a forced exhalation

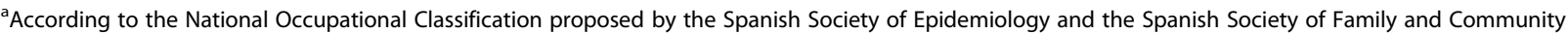
Medicine [41]

${ }^{\mathrm{b}}$ According to the WHO classifications of body weight [7] 
Table 2 Correlation between lung function and anthropometric parameters, overall and separately for men and women

\begin{tabular}{|c|c|c|c|c|c|}
\hline Variables & Weight & Height & $\mathrm{BMI}$ & Waist circumference & Waist-to-height ratio \\
\hline \multicolumn{6}{|c|}{ FVC \% Predicted } \\
\hline All & $-0.315^{* *}$ & $-0.203^{* *}$ & $-0.243^{* *}$ & $-0.261^{* *}$ & $-0.196^{* *}$ \\
\hline Women & $-0.241^{* *}$ & -0.079 & $-0.215^{* *}$ & -0.159 & -0.184 \\
\hline Men & $-0.203^{* *}$ & 0.024 & $-0.236^{* *}$ & $-0.267^{* *}$ & $-0.261^{* *}$ \\
\hline \multicolumn{6}{|c|}{ FEV1 \% Predicted } \\
\hline All & $-0.238^{* *}$ & $-0.201^{* *}$ & $-0.153^{* *}$ & $-0.209^{* *}$ & -0.132 \\
\hline Women & $-0.151^{*}$ & -0.089 & -0.115 & -0.087 & -0.087 \\
\hline Men & -0.134 & -0.001 & -0.148 & $-0.226^{* *}$ & $-0.218^{* *}$ \\
\hline \multicolumn{6}{|c|}{ FEV1/FVC ratio } \\
\hline All & 0.030 & $-0.137^{* *}$ & 0.122 & 0.011 & 0.074 \\
\hline Women & 0.121 & -0.073 & 0.163 & 0.127 & 0.173 \\
\hline Men & 0.120 & -0.001 & 0.131 & 0.001 & -0.018 \\
\hline
\end{tabular}

Values represent the correlation coefficients. ${ }^{*} p<0.05,{ }^{* *} p<0.001$

$B M I$, body mass index, FVC forced vital capacity, FEV1 maximum expiratory volume in the first second of a forced exhalation

Table 3 Multivariate linear regression analysis of lung function and anthropometric parameters, overall and separately for men and women

\begin{tabular}{|c|c|c|c|c|c|c|c|c|c|}
\hline \multirow[t]{2}{*}{ Variables } & \multicolumn{3}{|l|}{ Male } & \multicolumn{3}{|l|}{ Female } & \multicolumn{3}{|l|}{ All } \\
\hline & $\beta$ & $95 \% \mathrm{Cl}$ & $p$ values & $\beta$ & $95 \% \mathrm{Cl}$ & $p$ values & $\beta$ & $95 \% \mathrm{Cl}$ & $p$ values \\
\hline \multicolumn{10}{|l|}{ FVC \% Predicted } \\
\hline Waist-to-height & -61.48 & $-98.00,-24,96$ & 0.001 & -14.76 & $-36.94,7.41$ & 0.190 & -26.8 & $-46.61,-6.93$ & 0.002 \\
\hline Waist circumference & -0.39 & $-0.60,-0.18$ & $<0.001$ & -0.07 & -0.210 .07 & 0.328 & -0.22 & $-0.34,-0.10$ & $<0.001$ \\
\hline BMI, continuous & -0.79 & $-1.19,-0.39$ & $<0.001$ & -0.37 & $-0.67,-0.07$ & 0.016 & -0.59 & $-0.83,-0.34$ & $<0.001$ \\
\hline \multicolumn{10}{|l|}{ BMl categorization ${ }^{a}$} \\
\hline$<25.0 \mathrm{~kg} / \mathrm{m}^{2}$ & Ref. & Ref. & Ref. & Ref. & Ref. & Ref. & Ref. & Ref. & Ref. \\
\hline $25.0-29.9 \mathrm{~kg} / \mathrm{m}^{2}$ & -4.67 & $-8.67,-0.66$ & 0.023 & -1.51 & $-4.94,1.92$ & 0.388 & -4.21 & $-6.81,-1.60$ & 0.002 \\
\hline$\geq 30.0 \mathrm{~kg} / \mathrm{m}^{2}$ & -9.19 & $-13.82,-4.54$ & $<0.001$ & -3.21 & $-7.45,1.04$ & 0.138 & -67.25 & $-10.38,-4.13$ & $<0.001$ \\
\hline \multicolumn{10}{|l|}{ FEV1 \% Predicted } \\
\hline Waist-to-height & -59.91 & $-102.94,-16.88$ & 0.007 & -2.99 & $-27.32,21.34$ & 0.808 & -16.94 & $-39.77,5.88$ & 0.145 \\
\hline Waist circumference & -0.40 & $-0.65,-0.15$ & 0.002 & -0.02 & $-0.17,0.13$ & 0.787 & -0.20 & $-0.33,-0.06$ & 0.005 \\
\hline BMI, continuous & -0.52 & $-0.99,-0.05$ & 0.029 & -0.10 & $-0.41,0.22$ & 0.547 & -0.32 & $-0.59,-0.04$ & 0.024 \\
\hline \multicolumn{10}{|l|}{ BMI categorization ${ }^{a}$} \\
\hline$<25.0 \mathrm{~kg} / \mathrm{m}^{2}$ & Ref. & Ref. & Ref. & Ref. & Ref. & Ref. & Ref. & Ref. & Ref. \\
\hline $25.0-29.9 \mathrm{~kg} / \mathrm{m}^{2}$ & -0.78 & $-5.52,3.96$ & 0.609 & 1.43 & $-2.18,5.04$ & 0.436 & -1.01 & $-3.95,1.93$ & 0.502 \\
\hline$\geq 30.0 \mathrm{~kg} / \mathrm{m}^{2}$ & -5.39 & $-10.87,0.99$ & 0.054 & 0.08 & $-4.38,4.54$ & 0.971 & -2.77 & $-6.25,0.70$ & 0.118 \\
\hline \multicolumn{10}{|l|}{ FEV1/FVC ratio } \\
\hline Waist-to-height & 1.13 & $-17.93,20.20$ & 0.907 & 11.58 & $1.46,21.70$ & 0.025 & 9.58 & $-0.16,19.32$ & 0.054 \\
\hline Waist circumference & 0.01 & $-0.10,0.12$ & 0.917 & 0.05 & $-0.01,0.12$ & 0.113 & 0.02 & $-0.04,0.08$ & 0.512 \\
\hline BMI, continuous & 0.24 & $0.11,0.38$ & $<0.001$ & 0.31 & $0.11,0.50$ & 0.002 & 0.26 & $0.14,0.37$ & $<0.001$ \\
\hline \multicolumn{10}{|l|}{ BMI categorization ${ }^{a}$} \\
\hline$<25.0 \mathrm{~kg} / \mathrm{m}^{2}$ & Ref. & Ref. & Ref. & Ref. & Ref. & Ref. & Ref. & Ref. & Ref. \\
\hline $25.0-29.9 \mathrm{~kg} / \mathrm{m}^{2}$ & 3.76 & $1.79,5.73$ & $<0.001$ & 2.23 & $0.71,3.75$ & 0.004 & 2.43 & $1.20,3.65$ & $<0.001$ \\
\hline$\geq 30.0 \mathrm{~kg} / \mathrm{m}^{2}$ & 3.81 & $1.53,6.09$ & 0.001 & 3.10 & $1.17,4.93$ & 0.002 & 2.89 & $1.42,4.36$ & $<0.001$ \\
\hline
\end{tabular}

Adjusted by social class, smoking cumulative consumption, physical activity, alcohol consumption, medical history hypertension, diabetes mellitus and dyslipidemia

FVC Forced vital capacity, FEV1 Maximum expiratory volume in the first second of a forced exhalation; $\beta$ : regression coefficient for each exposure variable, $\mathrm{Cl}$ Confidence interval, $\mathrm{BMI}$ Body mass index

${ }^{a}$ According to the WHO classifications of body weight: normal weight $\left(<25.0 \mathrm{~kg} / \mathrm{m}^{2}\right)$, overweight $\left(25.0-29.9 \mathrm{~kg} / \mathrm{m}^{2}\right)$ and obese $\left(\geq 30.0 \mathrm{~kg} / \mathrm{m}^{2}\right)[7]$ 
WC, WHtR and pulmonary function. Furthermore, our results pertain to a specific cohort of adult smokers (aged 35-70 years), a population with a high risk of lung disease [2]. The relationship between smoking and worse lung function is no longer subject to debate, given the available epidemiological, morphological and genetic evidence. However, more recent studies are demonstrating the importance of additional factors such as abdominal adiposity markers [6]. It is possible that impaired lung function parameters were better associated with WC or WHtR than with BMI because smokers tend to have a lower BMI [23]. On the other hand, BMI is the only measure of obesity reported in several other populationbased studies $[8,24]$. Therefore, a strength of our work is that few studies have evaluated the association between WHtR and lung function.

Our study showed that highly specific markers of increased abdominal adiposity such as WC and/or WHtR, already proposed as better adiposity indicators than BMI $[13,25]$, were associated with lower $\mathrm{FVC} \%$ and $\mathrm{FEV} 1 \%$ values. Furthermore, a recent meta-analysis supports the use of WC as a pulmonary risk indicator because high WC values are associated with pulmonary dysfunction [13]. Results of the present study also support the use of WHtR as a new adiposity distribution marker involved in pulmonary function, amplifying the hypothesis previously tested for cardiovascular diseases [26]. Those authors recommend using WHtR, the correction of WC according to the height of the individual, because this measurement remains quite unchanged in adults, which reinforces the importance of changes in WC measurement. WHtR has been inversely associated with cardiovascular risk [25], and now also with lung function in the present study.

In our analysis stratified by sex, the inverse association of WC and WHtR with impaired lung function (FEV1\% and $\mathrm{FVC} \%$ ) was apparent in men but not in women. This finding is consistent with results from several other studies $[8,11,27,28]$, and supports the hypothesis that a sex-related difference in the pattern of fat distribution is one of the explanations for the sex difference in lung function impairment. Nonetheless, other studies have shown the opposite results. For example, in a cohort of patients with metabolic syndrome, pulmonary function was significantly lower in women than in men [29]. Although it was unclear why sex would be associated with differences in the effect of body fat distribution on pulmonary function, some possible explanations may be offered. Sex-based differences in lifestyle factors, hormonal system and pulmonary structure could affect pulmonary function. Another possible mechanism is a difference in how fat distribution associated with weight gain affects the thoracic mechanism in men vs. women, so that the location of fat deposition in women does not adversely affect lung function [24]. Cross-sectional and longitudinal studies of lung function suggest that the effects on respiratory mechanics might be more pronounced in men than in women for any given body fat distribution pattern $[9,11,27,28]$. It has also been suggested that lung function is influenced by sex differences, perhaps due to a lower functional impairment (smoke-induced) in women smokers, compared to men who smoke [30]; however, large epidemiological studies show that susceptibility to tobacco is similar in both sexes [31].

BMI category in smokers is associated with worse health status and impaired lung function. Recent findings delineate a "U-shaped" association between BMI and extreme weight categories, such that both the obese (BMI $\geq 30 \mathrm{~kg} / \mathrm{m}^{2}$ ) and the lean to underweight (BMI $<25 \mathrm{~kg} / \mathrm{m}^{2}$ ) smokers had lower FEV1 and worse health status [32]. In our study, the results confirm that overweight and obesity are positively associated with FEV1/ FVC ratio in both sexes. Some studies that included measurements of central adiposity have also observed that these tend to correlate with worse lung function, even in non-obese individuals [33]. However, other authors found no significant differences in FEV1/FVC ratio between obese and non-obese individuals [34]. Although the pattern of fat distribution appears to have a more significant influence on FEV1\% and FVC\% than more commonly used measures of general obesity such as continuous BMI, our results show that BMI $>25 \mathrm{~kg} / \mathrm{m}^{2}$ has a greater direct effect on the FEV1/FVC ratio. This spirometric variable discriminates obstructive ventilation disorder, while a reduction in $\mathrm{FVC} \%$ accompanies the reduction or maintenance of FEV1\%, suggesting a restrictive pattern that can be explained by the alteration in ventilator mechanics experienced by people with obesity $[35,36]$. When abdominal fat deposition occurs and BMI increases, the descent of the diaphragm during inspiration is limited, reducing the expiratory reserve volume by displacing the diaphragm upward and reducing functional volume in the thoracic cavity $[6,9,12]$. Another possible mechanism is that chest-wall adiposity may impede expansion and excursion of the rib cage, through a direct loading effect or by altering intercostal muscle function, which decreases inspiratory muscle activity $[37,38]$. In addition to these mechanical processes, lung function may also be affected by chronic low-grade inflammatory processes that accompany obesity. It has been shown that excess body fat is associated with markers of systemic and vascular inflammation such as $\mathrm{C}$ reactive protein, interleukin- 6 , tumour necrosis factor- $\alpha$, leptin and adiponectin [39]. As a whole, the available data confirm a much more complex relationship between anthropometric changes and lung function than can be ascribed solely to inflammatory effects, and growing evidence suggests that an interaction of adipokine disorder, 
mechanical disturbances and changes in muscle mass results in a combined effect on lung impairment and its manifestations [40].

\section{Conclusions}

In a Mediterranean population of smokers without respiratory symptoms, abdominal obesity has a negative impact on lung function. Central fat distribution appears to have a stronger relationship with pulmonary functional parameters in men than in women. In addition to BMI, other indexes of fat distribution (WC and WHtR) can be easily obtained during routine clinical practice and can be useful tools to indicate the advisability of carrying out a full assessment. Sensitization of primary care physicians to the identification of smokers with these conditions might increase referrals for lung function testing and lead to earlier diagnosis and appropriate patient management. What is known is that quitting smoking and losing weight are likely the best way to improve lung health in this rapidly growing patient population.

\section{Acknowledgements}

The study will be possible thanks to the generous collaboration of doctors and nurses from the Tarragona-Reus Primary Care Area (Catalan Health Institute) which constitute the participants of the ESPITAP Research Group. ESPITAP Study Group investigators: Aguirre-Alava G, Altamiras-Badia M, Alvarez-Soler E, Anguera-Perpiña C, Arnau-Adan V, Baiges-Folch M, Basora-Gallisa J, Berenguer-Atrio P, Bibiloni-Sole A, Blade-Creixenti J, Blanch-Aubia J, Boada-Tous A, Borras-Gavalda A, Borras-Vicente D, Cabre-Vila JJ, Camos-Guijosa P, CanalejoEscudero JJ, Cando-Guasch G, Castellar-Salinas MJ, Castro-Pamies R, Comino-Sillero L, Dalmau-Vidal S, DeAndres-DePablo MJ, DelPozo-Nubio J, Diego-Ferrer A, Duran-Visiedo JM, Elviro-Bodoy T, Ferrater-Cubells J, Ferre-Gras J, Fustero-Fustero I, Garcia-Aguila R, Garcia-Gonzalo C, Garcia-Masso A, Gens-Barbera M, Gil-Mancha S, Gil-Sanchez MD, Giner-Aguilo C, Giro-Guasch JM, Girona-Real R, Gomez-Santidrian F, Grau-Perez C, Grive-Isern M, Guinjoan-Aymemi N, Hernandez-Anguera JM, Hernandez-Lazaro E, Hernandez-Vidal N, Isach-Subirana A, Jovani-Puig MD, Juncosa-Cabre M, Lara-Pedrosa A, Lara-Pedrosa MT, Ledo-Garcia J, Lluis-Burgeño M, Lorente-Zozaya A, Mangrane-Ferrando M, Mangrane-Guillen C, Marimon-Barba J, Marti-Suau E, Martín-Lorente A, Martin-Vergara N, Martinez-Blesa MT, Martinez-Perez T, Mas-Escoda R, Medina-Clemente M, Mengual-Miralles M, Mora-Guilabert N, Moreno-Lagunas A, Ortega-Vila Y, Oya-Girona E, PalaciosLlamazares L, Palma-Jimenez MI, Pardo-Andujar J, Pascual-Palacios I, Pelleja-Pellicer ML, Perez-Bauer M, Perez-Galvez E, Pineda-Rigau T, PiñolMoreso JL, Poca-Pastor A, Prats-Caellas A, Profitos-Amiell R, Reche-Martinez A, Revuelta-Garrido V, Rey-Reñones C, Ribes-Arganuy M, Riera-Sole A, Rius-Fernandez B, Rubio-Gascon C, Sabate-Mestre J, Sagarra-Alamo R, Sanchez-Oro I, Sardaña-Alvarez E, Sarra-Manetas N, Sarre-Torra Y, Silva-Orjuela AR, Soler-Barreras P, Solis-Narvaez R, Subirats-Sanz E, Subirats-Segarra R, Tersa-Alcobe M, Timon-Torres M, Urbaneja-Diez A, Vazquez-Martinez O, Vers-Lopez O, Vila-Molet M, Vila-Rodrigo RV, Vizcaino-Marin J.

\section{Funding}

This study was made possible by a grant from the Institut Universitari d'Investigació en Atenció Primària Jordi Gol -IDIAP Jordi Gol. The Catalan Society of Primary Care-CAMFiC provided funding for the translation and publication of this article.

\section{Availability of data and materials}

The dataset supporting the conclusions of this article is available in the results section.

\section{Authors' contributions}

FML is the principal investigator. FML, MSA and RSA proposed the original idea and GFM contributed to the statistical analysis and drafted this manuscript. FML, MSA, RSA, GFM, CJP, EAL and JBG contributed to developing the study and critically revised the manuscript. All authors read and corrected draft versions, and approved the final version.

\section{Competing interests}

The authors declare that they have no competing interests.

\section{Consent for publication}

Not applicable.

\section{Ethics approval and consent to participate}

The study followed the principles contained in the Declaration of Helsinki and the Catalan Health Institute's Guidelines for Good Clinical Practice and successive revisions and the standards of good clinical practice. The protocol was approved by the Committee on Clinical Research Ethics (CEIC) of the Institut d'Investigació en Atenció Primària (IDIAP) Jordi Gol, and registered with the 4R07/040 identifier. All participants signed their informed consent prior to participation in the trial, and received information about the study: research objectives and activities included. Documentation was stored securely and was only available to authorized study personnel. We guaranteed data confidentiality in accordance with Spanish law on personal identity and data.

\section{Author details}

${ }^{1}$ Study Group on Respiratory Tract Diseases (GEPAR), Institut Universitari d'Investigació en Atenció Primària Jordi Gol (IDIAP Jordi Gol), Barcelona, Spain. ${ }^{2}$ Primary Healthcare Research Support Unit Tarragona-Reus, Institut Universitari d'Investigació en Atenció Primària Jordi Gol (IDIAP Jordi Gol), Reus, Spain. ${ }^{3}$ School of Medicine and Health Sciences, Universitat Rovira i Virgili, Tarragona, Spain. ${ }^{4}$ CAP Sant Pere - Institut Català de la Salut, C/Camí de Riudoms, 53-55, Reus 43203, Tarragona, Spain. ${ }^{5}$ CIBERobn

Physiopathology of Obesity and Nutrition, Institute of Health Carlos III (ISCIII), Madrid, Spain. ${ }^{6} \mathrm{NFOC}$ group School of Medicine and Health Sciences,

Universitat Rovira i Virgili, Tarragona, Spain.

Received: 7 April 2016 Accepted: 2 December 2016

Published online: 09 December 2016

\section{References}

1. WHO. World Health Organization. World halth statistics 2008. Geneva, World Health Organization, 2008. http://www.who.int/gho/publications/world_ health_statistics/PDF_ES_WHS08_Full.pdf. Accessed January 2016.

2. Vestbo J, Hurd SS, Agusti AG, Jones PW, Vogelmeier C, Anzueto A, et al. Global strategy for the diagnosis, management, and prevention of chronic obstructive pulmonary disease: GOLD executive summary. Am J Respir Crit Care Med. 2013;187:347-36.

3. Sato M, Shibata Y, Abe S, Inoue S, Igarashi A, Yamauchi K, et al. Retrospective analysis of the relationship between decline in FEV 1 and abdominal circumference in male smokers: the takahata study. Int J Med Sci. 2013;10:1-7.

4. McClean KM, Kee F, Young IS, Elborn JS. Obesity and the lung: 1. Epidemiology. Thorax. 2008;63:649-54.

5. Gabrielsen AM, Lund MB, Kongerud J, Viken KE, Røislien J, Hjelmesæth J. The relationship between anthropometric measures, blood gases, and lung function in morbidly obese white subjects. Obes Surg. 2011;21:485-91.

6. Littleton SW. Impact of obesity on respiratory function. Respirology. 2012;17:43-9.

7. World Health Organization. Obesity: preventing and managing the global epidemic. Report of a WHO consultation. World Health Organ Tech Rep Ser. 2000;894:1-253.

8. Jones RL, Nzekwu MM. The effects of body mass index on lung volumes. Chest. 2006;130:827-33.

9. Ochs-Balcom HM, Grant BJ, Muti P, Sempos CT, Freudenheim JL, Trevisan M, et al. Pulmonary function and abdominal adiposity in the general population. Chest. 2006;129:853-62.

10. Thyagarajan B, Jacobs DR, Apostol GG, Smith LJ, Jensen RL, Crapo RO, et al. Longitudinal association of body mass index with lung function: the CARDIA study. Respir Res. 2008;9:31. 
11. Steele RM, Finucane FM, Griffin SJ, Wareham NJ, Ekelund U. Obesity is associated with altered lung function independently of physical activity and fitness. Obesity. 2009;17:578-84.

12. Salome CM, King GG, Berend N. Physiology of obesity and effects on lung function. J Appl Physiol (1985). 2010;108:206-11.

13. Wehrmeister FC, Menezes AM, Muniz LC, Martínez-Mesa J, Domingues MR Horta BL. Waist circumference and pulmonary function: a systematic review and meta-analysis. Syst Rev. 2012;1:55.

14. Wei YF, Wu HD, Chang CY, Huang CK, Tai CM, Hung CM, et al. The impact of various anthropometric measurements of obesity on pulmonary function in candidates for surgery. Obes Surg. 2010;20:589-94.

15. Wei YF, Wu HD, Yung-Chieh Yen PD, Huang CK, Tai CM, Hsuan CF. The impact of metabolic parameters on the change of pulmonary function in obese patients. Surg Obes Relat Dis. 2014;10:23-8.

16. Lee CMY, Huxley RR, Wildman RP, Woodward M. Indices of abdominal obesity are better discriminators of cardiovascular risk factors than BMI: a meta-analysis. J Clin Epidemiol. 2008:61:646-53.

17. Martin-Lujan F, Piñol-Moreso JL, Martin-Vergara N, Basora-Gallisa J, PascualPalacios I, Sagarra-Alamo R, et al. Effectiveness of a structured motivational intervention including smoking cessation advice and spirometry information in the primary care setting: the ESPITAP study. BMC Public Health. 2011;11:859.

18. Miller MR, Crapo R, Hankinson J, Brusasco V, Burgos F, Casaburi R, et al. General considerations for lung function testing. Eur Respir J. 2005;26:153-61.

19. Miller MR, Hankinson J, Brusasco V, Burgos F, Casaburi R, Coates A, et al. Standardisation of spirometry. Eur Respir J. 2005:26:319-38.

20. Holm S. A simple sequantially rejective multiple test procedure. Scand J Stat. 1979:6:65-70.

21. Santana H, Zoico E, Turcato E, Tosoni P, Bissoli L, Olivieri M, et al. Relation between body composition, fat distribution, and lung function in elderly men. Am J Clin Nutr. 2001;73:827-31.

22. Wannamethee SG, Shaper AG, Whincup PH. Body fat distribution, body composition, and respiratory function in elderly men. Am J Clin Nutr. 2005:82:996-1003.

23. Chinn S, Jarvis D, Melotti R, Luczynska C, Ackermann-Liebrich U, Antó JM, et al. Smoking cessation, lung function, and weight gain: a follow-up study. Lancet. 2005;365:1629-35.

24. Bottai M, Pistelli F, Di Pede F, Carrozzi L, Baldacci S, Matteelli G, et al. Longitudinal changes of body mass index, spirometry and diffusion in a general population. Eur Respir J. 2002;20:665-73.

25. Ashwell M, Hsieh SD. Six reasons why the waist-to-height ratio is a rapid and effective global indicator for health risks of obesity and how its use could simplify the international public health message on obesity. Int J Food Sci Nutr. 2005;56:303-7.

26. Guasch-Ferré M, Bulló M, Martínez-González MÁ, Corella D, Estruch $R$, Covas Ml, et al. Waist-to-height ratio and cardiovascular risk factors in elderly individuals at high cardiovascular risk. PLoS One. 2012;7:e43275.

27. Harik-Khan RI, Wise RA, Fleg JL. The effect of gender on the relationship between body fat distribution and lung function. J Clin Epidemiol. 2001;54:399-406.

28. Koziel S, Ulijaszek SJ, Szklarska A, Bielicki T. The effects of fatness and fat distribution on respiratory functions. Ann Hum Biol. 2007;34:123-31.

29. Choi JH, Park S, Shin YH, Kim MY, Lee YJ. Sex differences in the relationship between metabolic syndrome and pulmonary function: the 2007 Korean national health and nutrition examination survey. Endocr J. 2011:58:459-65.

30. Mitsiki E, Bania E, Varounis C, Gourgoulianis Kl, Alexopoulos EC. Characteristics of prevalent and new COPD cases in Greece: the GOLDEN study. Int J Chron Obstruct Pulmon Dis. 2015;10:1371-82.

31. Kohansal R, Martinez-Camblor P, Agustí A, Buist AS, Mannino DM, Soriano JB. The natural history of chronic airflow obstruction revisited: an analysis of the Framingham offspring cohort. Am J Respir Crit Care Med. 2009;180:3-10.

32. Sood A, Petersen H, Meek P, Tesfaigzi Y. Spirometry and health status worsen with weight gain in obese but improve in normal-weight smokers. Am J Respir Crit Care Med. 2014;189:274-81.

33. Chen Y, Rennie D, Cormier YF, Dosman J. Waist circumference is associated with pulmonary function in normal-weight, overweight, and obese subjects. Am J Clin Nutr. 2007;85:35-9.

34. Al GM. The effect of obesity on spirometry tests among healthy non-smoking adults. BMC Pulm Med. 2012;12:10

35. Leone N, Courbon D, Thomas F, Bean K, Jégo B, Leynaert B, et al. Lung function impairment and metabolic syndrome: the critical role of abdominal obesity. Am J Respir Crit Care Med. 2009;179:509-16.
36. Çolak Y, Marott JL, Vestbo J, Lange P. Overweight and obesity may lead to under-diagnosis of airflow limitation: findings from the Copenhagen City Heart Study. COPD. 2015;12:5-13.

37. Poulain M, Doucet M, Major GC, Drapeau V, Sériès F, Boulet LP, et al. The effect of obesity on chronic respiratory diseases: pathophysiology and therapeutic strategies. CMAJ. 2006;174:1293-9.

38. Chlif M, Keochkerian D, Feki Y, Vaidie A, Choquet D, Ahmaidi S. Inspiratory muscle activity during incremental exercise in obese men. Int J Obes (Lond). 2007;31:1456-63.

39. Gan WQ, Man SF, Sin DD. The interactions between cigarette smoking and reduced lung function on systemic inflammation. Chest J. 2005;127:558-64.

40. Suratt BT. Weight gain and lung disease: the vagary of body mass index and the dilemma of the obese smoker. Am J Respir Crit Care Med. 2014;189:240-2

41. Domingo-Salvany A, Regidor E, Alonso J, Alvarez-Dardet C. Proposal for a social class measure. Working group of the Spanish society of epidemiology and the Spanish society of family and community medicine. Aten Primaria. 2000;25:350-63.

\section{Submit your next manuscript to BioMed Central and we will help you at every step:}

- We accept pre-submission inquiries

- Our selector tool helps you to find the most relevant journal

- We provide round the clock customer support

- Convenient online submission

- Thorough peer review

- Inclusion in PubMed and all major indexing services

- Maximum visibility for your research

Submit your manuscript at www.biomedcentral.com/submit
) Biomed Central 